\title{
Promises to keep: speech acts and the value of reflective knowledge ${ }^{*}$
}

JOHN TURRI

john.turri@gmail.com

Abstract: This paper offers a new account of reflective knowledge's value, building on recent work on the epistemic norms of speech acts. Reflective knowledge is valuable because it licenses us to make guarantees and promises.

Keywords: knowledge account of assertion, epistemic norms, epistemic value, guaranteeing, reflective knowledge, Ernest Sosa

\section{Introduction}

Recently epistemologists have been preoccupied with questions about epistemic value and norms (e.g. Williamson 2000, DePaul 2001, Kvanvig 2003, Sosa 2007, Hawthorne and Stanley 2008, Riggs 2008, Zagzebski 2009, Haddock, Miller and Pritchard 2010, Turri 2011). In this paper, I explore one way that these issues intersect, which promises to shed new light on a perennial epistemological issue, namely, the distinction between animal and reflective knowledge. I argue that reflective knowledge is valuable at least in part because it licenses us to make guarantees and promises.

This is the penultimate version of a paper forthcoming in Logos \& Episteme. 


\section{Animal and reflective knowledge}

Many distinguished philosophers have distinguished between animal knowledge and reflective knowledge (e.g. Descartes 1641: 83, Peirce 1955: chapters 8 and 9, Russell 1949: 202, 451-2, and Sellars 1975: Lecture 1, esp. §33, p. 304). But Ernest Sosa is most closely identified with the distinction, having made it a central and enduring plank in his important and influential epistemology, and having done more than anyone to clarify the distinction and demonstrate its philosophical utility (Sosa 1991, 1997a, 1997b, 2004, 2007). Accordingly I will take Sosa's treatment as the starting point of my discussion, the ultimate goal being to help explain the value of reflective knowledge.

Animal knowledge is simple first-order knowledge unaided by explicit or implicit reflection on our cognitive powers or how the current circumstances affect their operation. It includes many ordinary beliefs formed on the basis of perception, memory and introspection. Reflective knowledge requires a true second-order belief that your first-order belief amounts to knowledge (Sosa 2007: 32). ${ }^{1}$ It involves, to one degree or another, reflection on our cognitive powers and how the current environment affects their operation.

Sosa gives "pride of place" to reflective knowledge (2004: 291), judging it "an important epistemic desideratum," more worthy than the merely animal (2009: 144). And Sosa is not alone here. As men-

1 Sosa 2009: 141 defines "human knowledge" as "apt belief aptly noted," a characterization previously reserved for "reflective knowledge" (see Sosa 2007: 32). But context reveals that he is here just aiming to avoid what he sees as a merely terminological dispute with opponents. 
tioned earlier, Descartes, Peirce, Russell, Sellars and others have adopted a similar bi-level epistemology, with special (in some cases, nearly exclusive) distinction attaching to the higher-level intellectual achievement. ${ }^{2}$ But some have questioned the relative importance and worth of reflective knowledge (e.g. Kornblith 2004, Greco 2004, 2006). What makes reflective knowledge distinctive? What sets it apart from plain old knowledge? Why should we care about it?

Sosa replies to these questions with three points (2004: 291-2). First, reflective knowledge is more closely connected to intellectual autonomy, which we value. Second, the claim that reflective knowledge is specially important best explains the perennial fascination with certain forms of skepticism, especially the Pyrrhonian sort. Third, reflection and reflective knowledge enhances practical autonomy, "the whole person's" ability to control her conduct, rather than her conduct being the mechanical effect of cognitive modules such as vision or memory. There might be room to contest each of these three points, but that's not my purpose here. Instead I offer an additional, complementary proposal.

Sosa is keenly aware of how deeply knowledge is intertwined with the social (see e.g. Sosa 1991: 26, 48-9, 275-6). But one important social aspect of knowledge does not figure into his response, namely, its role in licensing speech. In what follows, I will develop this neglected possibility by suggesting that reflective knowledge's special status derives at least partly from its role in li-

2 Sosa $1997 \mathrm{~b}$ defends this reading of Descartes. 
censing important speech acts, which facilitate valuable social activities and relationships.

\section{Assertion and the value of knowledge}

I take as my starting point the well supported-though by no means uncontested-claim that you may assert something only if you know it. Call this the knowledge account of assertion, or 'KA' for short. ${ }^{3}$

As far back as Plato's Meno, philosophers have wondered why knowledge is more valuable than mere true belief. If a true belief that this is the road to Larissa will get you to Larissa just as well as knowledge that this is the road to Larissa, Plato wondered, then why is knowledge better than mere true belief? Following Duncan Pritchard (2009: 3), we can call this the primary value problem. A different question is what Pritchard calls the secondary value problem: why is knowledge "more valuable than any proper subset of its parts"? (Compare Kvanvig 2003.) For instance, if justified true belief is necessary but not sufficient for knowledge, then why is knowledge more valuable than justified true belief? Furthermore, many thinkers believe that knowledge has, as Pritchard puts it, a "distinctive value," meaning that it is better than true belief, and justified true belief, not just in degree, but also in kind. Accordingly Pritchard identifies the tertiary value problem, which is to explain

3 For defense of KA, see Unger 1975: Chapter VI, Williamson 2000: Chapter 11, DeRose 2002, Reynolds 2002, Turri 2010b, Turri 2011, and Benton 2011. For criticism of KA, see Weiner 2005, Douven 2006, Lackey 2007, Hill and Schechter 2007, Levin 2008, Kvanvig 2009, Brown 2010, and McKinnon forthcoming. 
"why knowledge has not just a greater degree but also a different kind of value than whatever falls short of knowledge" (2009: 4).

KA helps solve all three problems at once. Knowledge, and no epistemic status short of it, licenses assertion, which speaks to the primary and secondary problems. The difference between having and lacking permission is a difference in kind, not degree, which speaks to the tertiary problem. But even setting aside Pritchard's tripartite classification of problems, KA enables a simple and straightforward explanation of why we value knowledge. Assertion is the primary means of expressing and sharing information, which is essential to the welfare of rational social beings like us. So if knowledge is the norm of assertion, then its value derives at least partly from its role in licensing this vital social activity. And given how important assertion is, surely KA enables us to, as Pritchard enjoins, explain why "the long history of epistemological discussion has focused specifically on the stage in [the] continuum of epistemic value that knowledge marks rather than some other stage (such as a stage just before the one marked out by knowledge, or just after)" (2009: 4$){ }^{4}$

4 This last consideration fails, however, to meet one further constraint that Pritchard thinks an explanation of knowledge's value might strive to respect. The further constraint is that knowledge is "somehow precious, in the sense that its value is not merely a function of its practical import," but is instead "non-instrumentally valuable" (2009: 4). However, I am not persuaded that we should accept this last constraint. Whereas there is a robust intuitive basis for claiming that knowledge is somehow intellectually better than mere true belief, and (once apprised of the Gettier problem) better than mere justified true belief, I don't likewise think there is a robust intuitive basis for claiming that knowledge is distinctively, non-instrumentally valuable. That is a highly theoretical claim, which stands in need of argu- 
John Turri

\section{Alethic speech acts}

Now let's consider more carefully what sort of speech act assertion is. Doing so will help us understand how it relates to other speech acts and thereby give us some insight into their epistemic norms, which will in turn suggest a distinctive source of reflective knowledge's value.

Other things being equal, insofar as an assertion is true, it is good qua assertion; insofar as it is false, it is bad qua assertion (Williamson 2000: 244ff). In virtue of this, let's say that assertion aims at truth. Other speech acts also aim at truth, such as guessing, conjecturing and guaranteeing. Call speech acts aimed at truth alethic speech acts.

Alethic speech acts differ in two important, closely related ways. First, some place more credibility on the line than others. Guessing extracts little if any of your credibility. Let a pure blind guess be a guess where your total evidence is indifferent among any and all relevant options. Pure blind guessing extracts no credibility and so carries no epistemic requirement. You are required, at most, only to not guess against your evidence. ${ }^{5}$ Conjecturing extracts more credibility than guessing, asserting more than conjecturing, and guaranteeing more than asserting. Our evidence for sorting alethic speech acts in this way is both phenomenological and practical. On the one

mentation. Thanks to Duncan Pritchard for discussion on this point.

5 Suppose you're asked to guess whether Q or R. Arguably, if your evidence on balance indicates that one of the options is more likely, then you ought to guess that option, and if you guess otherwise, then the resulting guess would to that extent be bad. 
hand, we feel the difference between saying 'I guess that Q', 'Q', and 'I guarantee that Q'. We're prone to feel more anxiety as we move from guessing to asserting, or from asserting to guaranteeing. On the other hand, we're entitled to hold people to greater account when they guarantee that something is true than when they merely assert it, and the same is true when they assert it compared to when they merely guess it. ${ }^{6}$ If I guarantee that McCain will win, whereas you merely assert that McCain will win, and Jones simply guesses that McCain will win, then when it turns out that McCain doesn't win, I lose more credibility than you do, and you more than Jones. Moreover, in the case of a pure blind guess, we're not entitled to hold someone to account at all. If you say 'This is a pure blind guess: Q', and it turns out that Q is false, then it would be completely out of line for me to place less credibility in your future word as a result. To approach the matter slightly differently, consider that we feel more confident purchasing a product when the manufacturer guarantees that it will work, than when the manufacturer simply says that it will work. And we in turn would feel more confident when the manufacturer says that it will work, than when the manufacturer guesses that it will work.

Second, the more credibility an alethic speech act extracts, the stricter the epistemic norms governing it (Turri 2010a). Guessing requires virtually nothing by way of evidence or epistemic standing.

6 Plausibly the practical and phenomenological points are related. The practical point probably explains why we feel more anxiety as we move up the scale of alethic speech acts. Interesting as this is in its own right, I won't pursue the matter further here. 
Conjecturing requires that you have at least some evidence favoring $\mathrm{Q}$, and perhaps that $\mathrm{Q}$ be the most probable alternative given your evidence. Henry Jekyll suggests as much when he writes to Mr. Utterson: "I must here speak by theory alone, saying not that which I know, but that which I suppose to be most probable." 7 As already noted, knowledge is the norm of assertion. Some alethic speech acts are more emphatic than assertion, and they extract more credibility than does assertion. Call such speech acts ultra-assertive. Guaranteeing is ultra-assertive. Just as conjecturing has a stricter epistemic norm than guessing, and asserting a stricter norm than conjecturing, we should expect ultra-assertive speech acts to have stricter epistemic norms still. So guaranteeing requires more than knowledge. Call a state or requirement more demanding than knowledge ultra-epistemic. One ultra-epistemic state available to warrant ultra-assertive speech acts is knowledge of knowledge, a possibility we turn to next.

\section{Promising and the value of reflective knowledge}

John Austin (1946) claimed that asserting that you know $Q$ counts as guaranteeing that $Q$. Wilfrid Sellars (1975) argued that 'I know that Q' means the same thing as ' $Q$, and I have reasons good enough to guarantee that Q'. I disagree with Austin and Sellars on the nature of the connection between asserting that you know and guaranteeing, though I do agree with them that there's clearly an im-

7 See the final section of Stevenson 1886: "Henry Jekyll's Full Statement of the Case." 
portant intuitive connection between them. But what is the connection? If knowing that you know were the epistemic norm of guaranteeing, then we could explain the intuitive connection as follows. When you assert that you know Q, you represent yourself as having the authority to assert that you know Q. Given that knowledge is the norm of assertion, this amounts to representing yourself as knowing that you know Q. So if knowing that you know is the norm of guaranteeing, then by asserting that you know Q, you represent yourself as having the authority to guarantee $Q .{ }^{8}$

Call the KK account of guaranteeing the view that you may guarantee something only if you know that you know it. The KK account and the definition of reflective knowledge together entail that reflective knowledge is the norm of guaranteeing.

Now we're positioned to explain reflective knowledge's special status, in much the same way we earlier explained knowledge's value. Reflective knowledge is important because it enables us to engage in the important social practice of guaranteeing. A promise is plausibly regarded as a special type of guarantee, perhaps distinguished by being properly offered only when the promisor and promisee are somehow intimate. ${ }^{9}$ Guarantees and promises are essential to accomplishing our goals in some contexts, and are integ-

8 I defend this line of reasoning in Turri forthcoming.

9 The OED defines 'promise' (n.) like so, "A declaration or assurance made to another person (usually with respect to the future), stating a commitment to give, do, or refrain from doing a specified thing or act, or guaranteeing that a specified thing will or will not happen" (emphasis added). Here I'm thinking of propositional promising (i.e. promising that), rather than infinitive promising (i.e. promising to). 
ral to the health and maintenance of important relationships. Sometimes we find ourselves faced with a skeptical or hesitant fellow whose help we need, but who won't be satisfied with anything less than a proper guarantee that things will turn out a certain way. Merely asserting that they'll turn out that way isn't enough to reassure him. And many are the times when a promise helps reassure a frightened child, timorous friend or worried spouse.

Note a further dimension of my proposal. Guarantees come in degrees. ${ }^{10}$ You can guarantee, emphatically guarantee and absolutely guarantee. Emphatically or absolutely guaranteeing extracts more credibility than merely guaranteeing. And it is of course natural to suppose that the more emphatic the guarantee, the more robust the epistemic requirement licensing it. Reflective knowledge likewise comes in degrees (Sosa 2007, 2009). ${ }^{11}$ You can reflectively know something better or worse. The gradability of reflective knowledge can thus match that of a guarantee's strength: the stronger the guarantee, the better the reflective knowledge required to license it.

Even setting aside the KK account, context certainly often requires us to do more than merely assert something to persuade our intended audience: we are challenged to stand by our words, or have our authority to make an assertion disputed. Having reflective knowledge-knowing that you know-positions you to properly handle such challenges. And so long as reflective knowledge suffices

${ }^{10}$ This is true of conjecture, assertion and swearing as well.

${ }^{11}$ Its degree is a function of a number of things, including the levels of reflective ascent, the scope and depth of the reflection involved, the variety and severity of the challenges to which it enables a response, and the reliability of the cognitive dispositions exercised in reflection. 
here, or even normally enables a successful response, then even if it isn't strictly necessary, it would be valuable indeed and certainly something we theorists could profitably study.

This last suggestion is at least broadly related to Sosa's views on reflective knowledge's place in properly understanding and responding to skepticism. But my proposal gets traction even prior to reflection on skepticism, because the challenges I speak of are a common part of ordinary life, and so provide a broad and robust vindication of reflective knowledge's value.

\section{Conclusion}

In sum, reflective knowledge is special in no small part because it licenses important ultra-assertive speech acts, such as guaranteeing and promising. I conclude that we've located a plausible source of reflective knowledge's special status. ${ }^{12}$

${ }^{12}$ For helpful feedback and conversation, I thank Matthew Benton, Ian MacDonald, Rhys McKinnon, Duncan Pritchard, Ernest Sosa and Angelo Turri. This research was supported by the Social Sciences and Humanities Research Council of Canada. 


\section{References}

Austin, J.L. 1946. "Other Minds." Proceedings of the Aristotelian Society, Supplementary Volumes 20: 148-187.

Benton, Matthew. 2011. "Two More for the Knowledge Account of Assertion." Analysis 71, 684-687.

Brown, Jessica. 2010. "Knowledge and Assertion." Philosophy and Phenomenological Research 81, 549-566.

DePaul, Michael. 2001. "Value Monism in Epistemology." In Knowledge, Truth, and Duty. Ed. Matthias Steup. Oxford: Oxford University Press.

DeRose, Keith. 2002. "Assertion, Knowledge and Context." Philosophical Review 111, 167-203.

Descartes, Rene. 1641. Meditations, Objections and Replies. Ed. and trans. Roger Ariew and Donald Cress. Indianapolis: Hackett.

Douven, Igor. 2006. "Assertion, Knowledge, and Rational Credibility." Philosophical Review 115, 449-85.

Greco, John. 2004. "How to Preserve Your Virtue while Losing Your Perspective." In Ernest Sosa and His Critics. Ed. John Greco. Malden, Mass.: Blackwell.

Greco, John. 2006. "Virtue, Luck and the Pyrrhonian Problematic." Philosophical Studies 130, 9-34.

Haddock, Adrian, Alan Millar and Duncan Pritchard. 2010. The Nature and Value of Knowledge: Three Investigations. Oxford: Oxford University Press.

Hawthorne, John and Jason Stanley. 2008. "Knowledge and Action." Journal of Philosophy 105.10, 571-90.

Hill, Christopher S. and Joshua Schechter. 2007. "Hawthorne's Lottery Puzzle and the Nature of Belief." Philosophical Issues 17, 102-122.

Kornblith, Hilary. 2004. "Sosa on Human and Animal Knowledge." In Ernest Sosa and His Critics. Ed. John Greco. Malden, Mass.: Blackwell.

Kvanvig, Jonathan. 2003. The Value of Knowledge and the Pursuit 
of Understanding. Cambridge: Cambridge University Press.

Kvanvig, Jonathan. 2009. “Assertion, Knowledge, and Lotteries.” In Williamson on Knowledge. Ed. Duncan Pritchard and Patrick Greenough. Oxford: Oxford University Press.

Lackey, Jennifer. 2007. "Norms of Assertion.” Noûs 41, 594-626.

Levin, Janet. 2008. "Assertion, Practical Reason, and Pragmatic Theories of Knowledge." Philosophy and Phenomenological Research 76, 359-384.

McKinnon, Rhys. Forthcoming. "How Do You Know that 'How Do You Know?' Challenges a Speaker's Knowledge?” Pacific Philosophical Quarterly.

Peirce, Charles. 1955. Philosophical Writings of Peirce. Ed. Justus Buchler. New York: Dover.

Pritchard, Duncan. 2009. "The Value of Knowledge." The Harvard Review of Philosophy 16, 2-19

Reynolds, Steven L. 2002. "Testimony, Knowledge, and Epistemic Goals." Philosophical Studies 110, 139-161.

Riggs, Wayne. 2008. “The Value Turn in Epistemology.” In New Waves in Epistemology. Ed. Vincent Hendricks and Duncan Pritchard. New York: Palgrave Macmillan.

Russell, Bertrand. 1948 [1992 reprint]. Human Knowledge: Its Scope and Limits. New York: Routledge.

Sellars, Wilfrid. 1975. "The Structure of Knowledge: (I) Perception; (II) Minds; (III) Epistemic Principles.” In Action, Knowledge and Reality: Studies in Honor of Wilfrid Sellars, ed. H. N. Castañeda. New York: Bobbs-Merill.

Sosa, Ernest. 1991. Knowledge in Perspective. Cambridge: Cambridge University Press.

Sosa, Ernest. 1997a. "Reflective Knowledge in the Best Circles." The Journal of Philosophy 94, 410-430.

Sosa, Ernest. 1997b. "How to Resolve the Pyrrhonian Problematic: A Lesson from Descartes." Philosophical Studies 85, 229249. 
Sosa, Ernest. 2004. "Replies." In Ernest Sosa and His Critics. Ed. John Greco. Malden, Mass.: Blackwell.

Sosa, Ernest. 2007. A Virtue Epistemology: Apt Belief and Reflective Knowledge, Volume 1. Oxford: Oxford University Press.

Sosa, Ernest. 2009. "Replies to Commentators on A Virtue Epistemology." Philosophical Studies 144, 137-47.

Stevenson, Robert Louis. 1886 [1991 reprint]. The Strange Case of Dr. Jekyll and Mr. Hyde. Mineola, New York: Dover.

Turri, John. 2010a. "Epistemic Invariantism and Speech Act Contextualism." Philosophical Review 119, 77-95.

Turri, John. 2010b. "Prompting Challenges." Analysis 70.3, 456462

Turri, John. 2011. "The Express Knowledge Account of Assertion." Australasian Journal of Philosophy 89, 37-45.

Turri, John. Forthcoming. "Knowledge Guaranteed.” Noûs.

Unger, Peter. 1975. Ignorance: A Case for Skepticism. Oxford: Oxford University Press.

Weiner, Matthew. 2005. "Must We Know What We Say?" The Philosophical Review 114, 227-251.

Williamson, Timothy. 2000. Knowledge and Its Limits. Oxford: Oxford University Press.

Zagzebski, Linda. 2009. On Epistemology. Belmont, Calif.: Wadsworth. 